\title{
The search for relevant outcome measures for cost-utility analysis of systemic family interventions in adolescents with substance use disorder and delinquent behavior: a systematic literature review
}

\author{
S. Schawo ${ }^{1 *}$, C. Bouwmans ${ }^{1}$, E. van der Schee ${ }^{2}$, V. Hendriks ${ }^{2,3}$, W. Brouwer ${ }^{1}$ and L. Hakkaart ${ }^{1}$
}

\begin{abstract}
Purpose: Systemic family interventions have shown to be effective in adolescents with substance use disorder and delinquent behavior. The interventions target interactions between the adolescent and involved systems (i.e. youth, family, peers, neighbors, school, work, and society). Next to effectiveness considerations, economic aspects have gained attention. However, conventional generic quality of life measures used in health economic evaluations may not be able to capture the broad effects of systemic interventions. This study aims to identify existing outcome measures, which capture the broad effects of systemic family interventions, and allow use in a health economic framework.

Methods: We based our systematic review on clinical studies in the field. Our goal was to identify effectiveness studies of psychosocial interventions for adolescents with substance use disorder and delinquent behavior and to distill the instruments used in these studies to measure effects. Searched databases were PubMed, Education Resource Information Center (ERIC), Cochrane and Psychnet (PsycBOOKSc, PsycCRITIQUES, print). Identified instruments were ranked according to the number of systems covered (comprehensiveness). In addition, their use for health economic analyses was evaluated according to suitability characteristics such as brevity, accessibility, psychometric properties, etc.

Results: One thousand three hundred seventy-eight articles were found and screened for eligibility. Eighty articles were selected, 8 instruments were identified covering 5 or more systems.

Conclusions: The systematic review identified instruments from the clinical field suitable to evaluate systemic family interventions in a health economic framework. None of them had preference-weights available. Hence, a next step could be to attach preference-weights to one of the identified instruments to allow health economic evaluations of systemic family interventions.
\end{abstract}

Keywords: Economic evaluation, Instrument, Externalizing, Mental health, Youth

\section{Background}

Systemic family interventions are psychotherapeutic treatments, which are increasingly used to treat children and adolescents with mental disorders. These interventions are based on the idea that the behavior of a patient is the result of interactions between himself and the

\footnotetext{
* Correspondence: schawo@bmg.eur.nl

${ }^{1}$ Institute for Medical Technology Assessment \& Institute of Health Policy \& Management, Erasmus University Rotterdam, P.O. Box 1738, 3000 DR Rotterdam, The Netherlands

Full list of author information is available at the end of the article
}

different 'systems' he is involved in (i.e. family, peers, school, etc.) and of the interactions between these systems [1-3]. Treatment is directed at improving the disturbing aspects within these interactions [3] and it actively involves the systemic context of the patient. Hence, potential effects are broad and may range from improvements in the interactions with parents, other family members, peers or neighbors, to improvements in educational achievements and work relations, reduction of criminal activity and substance use and reduction of 
problems with the juvenile justice system $[2,4-6]$. Systemic family interventions have shown particularly effective in the treatment of adolescents with substance use disorders and delinquency [7-10]. Examples of these interventions are Multisystemic Therapy (MST), Functional Family Therapy (FFT), Multidimensional Family Therapy (MDFT) and Brief Strategic Family Therapy (BSFT) [7-10].

With the increasing use of systemic family interventions, the question of funding and reimbursement arises. In some countries, like the Netherlands or the United Kingdom, systemic family interventions are reimbursed from social health insurance schemes and, as such, are part of collectively financed health care. Hence, the interventions compete for limited funds with other health care expenditures and, on top of proving effective, need to demonstrate value for money. Common practice in the economic evaluation of medical interventions is the use of cost-utility analysis (CUA) $[11,12]$ measuring effects in terms of Quality-Adjusted Life-Years (QALYs). QALYs combine length and quality of life gained. Typically, quality of life is measured through preferencebased, generic health outcome measures (such as the EQ-5D). These outcome measures typically concentrate on improvements in a number of health domains. A recent publication of our department [13] described the results of a CUA of MDFT versus Cognitive Behavioral Therapy (CBT) in which the effects were measured with the EQ-5D. Yet, in the field of mental health, doubts have been expressed $[14,15]$ on the use of these generic quality of life measures [16] as these tools might be too limited to cover all relevant treatment effects. Studies on the applicability of these measures in mental health have presented mixed results $[14,15]$. Furthermore, there is increasing attention for the inclusion of spillover effects on caregivers and families in economic evaluations. Currently, these effects are not yet included $[17,18]$, though they may be particularly important in treatment of younger patients. Recently, the Second Panel of CostEffectiveness in Health and Medicine has recommended further research on quality of life effects on family members of patients [19].

Both aspects, the assessment of effects specific to mental health treatments and the inclusion of (partial) effects on third parties, seem of particular relevance to the economic evaluation of systemic interventions in delinquency and substance use in adolescents. As outcomes of systemic family interventions are broad and transcend health gains, conventional CUA outcome measures may be too limited and insufficiently connected to clinical practice. This may be one of the reasons why economic evaluations of systemic interventions are still scarce and overall of low quality [20]. Existing economic evaluations of these interventions vary in setting, design and in outcomes measured [20] hence limiting the comparability of results. Furthermore, few studies consider effects on others than the patient [1].

If the aim is to perform economic evaluations of systemic family interventions which account for all relevant effects, a disorder-specific multidimensional measure that captures all relevant systemic contexts would be desirable. Ideally, if such a measure had societal preference-weights attached to its dimensions and levels, it would deviate from the common CUA methodology yet enable CUAlike economic evaluations. In patients with substance use disorder (one of the patient groups treated with systemic family interventions), the need for such a single comprehensive outcome measure capturing the full benefits of treatments has been recognized before [21]. Deas and Thomas [22] and Hogue and Liddle [23] emphasized the necessity of assessing various outcomes beyond effects in the adolescent. In an illustrative pilot study, Jofre-Bonet and Sindelar [21] presented a first example of a preference-based measure for adult populations with substance abuse. However, that measure was not based on standard preference-elicitation techniques but the authors attached patient preference-weights to the eight main domains of the Addiction Severity Index (ASI) [24] by constructing a weight index.

In the current study, we take this line of research further by searching for a multidimensional outcome measure to evaluate systemic family interventions in the populations of adolescents with substance abuse disorder or problems of delinquency. Such a measure could facilitate CUAs of systemic family interventions and could either be based on existing effectiveness measures in this field or fully designed anew. In both cases, the use of an existing measure or the design of a new measure, relevant domains would need to be identified. Based on consultation of the literature on systemic family interventions $[1$, $25,26]$ the domains relating to aspects of the individual patient, family, school (or work) and other community environments (e.g. peers, neighbors) were considered most relevant to the evaluation of the interventions. Figure 1 provides a graphical illustration of these domains, which indicate where potential effects may occur. The strength of the impact on the different systems may obviously differ, depending on the exact underlying problems and other contextual factors.

We perform a systematic literature review to investigate and appraise available instruments in the field of adolescent delinquency and substance use, which cover the relevant domains and which are already accepted and validated in the field. We assess which of these instruments might be most suited to serve as a basis for a preference-based measure in CUA, based on characteristics like comprehensiveness, brevity, accessibility, psychometric properties, etc. Advantage of using an existing instrument would be its being established, accepted and 


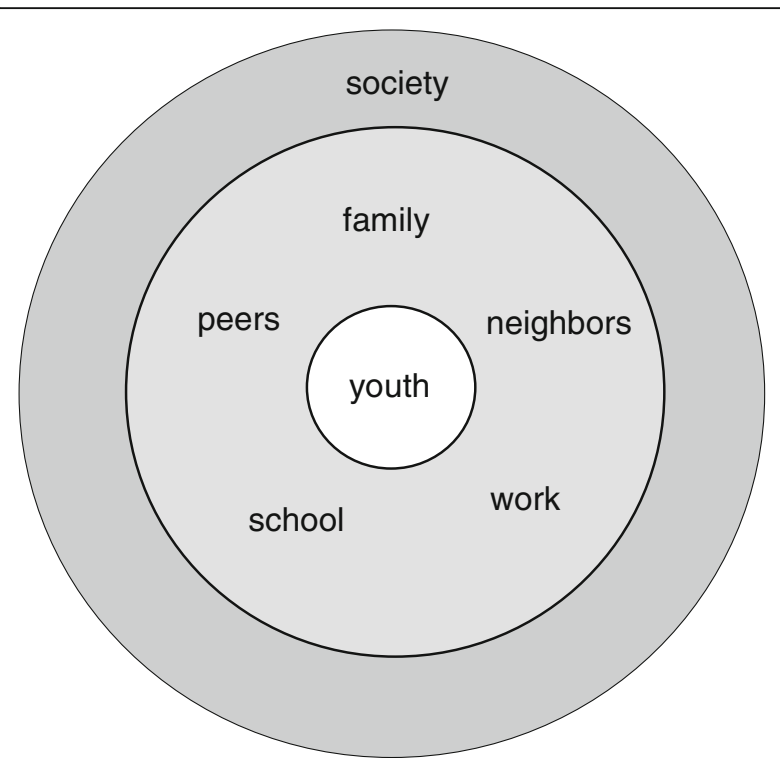

Fig. 1 Systems involved in systemic family interventions for treatment of delinquency and substance-abuse in adolescents

validated in the field and known by clinicians. It would then only be necessary to add preference-weights to the domains to account for differences in impact of each domain. In this way we aim to contribute to the development of adequate outcome measures to assess the economic value of systemic family interventions in the treatment of delinquency and substance use.

\section{Methods}

We conducted a systematic literature review to identify instruments within the effectiveness and efficacy literature of mental health interventions for adolescents with substance use disorder and delinquency problems. We then assessed the suitability of these instruments for use of preference elicitation techniques. The assessment was based on several characteristics relevant to attain societal preference weights. These characteristics were among others the coverage of the systems displayed in Fig. 1 (i.e. youth, family, peers, school, work, society and neighbors), brevity, practicability of use, accessibility, psychometric properties and acceptance in the field. The review protocol was not registered. Yet, this study adhered to the PRISMA reporting guidelines [27].

\section{Criteria for inclusion}

\section{Types of participants}

The target population of the systematic literature review consisted of adolescents between 12 and 18 years of age with symptoms of delinquency and/or substance use. Patients from specific sub-groups (e.g. homeless or runaway adolescents or adolescents with substance use disorder and comorbid depression) were excluded. As studies focusing on these subgroups evaluated specific outcomes, which were not necessarily relevant for the entire population of adolescents with substance use disorders and delinquent behavior, these studies were not considered relevant for the current study.

\section{Types of interventions}

We included studies on various mental health interventions for adolescents with substance use disorder or delinquency in a therapy/counseling setting in the systematic search to cover as many instruments as possible in the relevant target population. Individual interventions as well as systemic family interventions were included. Examples of such interventions are Cognitive Behavioral Therapy (CBT), Motivational Enhancement Therapy (MET), Multidimensional Family Therapy (MDFT), Multi Systemic Therapy (MST), Functional Family Therapy (FFT) and Ecologically Based Family Therapy (EBFT). Two types of interventions were excluded. First, interventions in mental health care that consisted of only pharmacotherapy were excluded since the focus of our study was specifically on the effect of psychosocial interventions. Second, mental health interventions for the prevention of criminal behavior or substance use disorder were excluded, as the symptoms within this group (i.e. high risk behavior or general behavioral problems) were not considered severe enough to fit the definition of the target population.

\section{Types of outcome measures}

Our objective was to identify a wide array of instruments used to measure the effect of mental health interventions for adolescents with substance use disorders and delinquent behavior. Hence, we included studies with all measures of effectiveness and treatment outcome as well as efficacy studies.

\section{Search methods for identification of studies}

Databases were selected as to cover both interventions in the medical and in the educational field. The systematic literature review was performed in PubMed, Psychnet (PsycBOOKSc, PsycCRITIQUES, print), Cochrane and ERIC (Education Resource Information Center) to identify all effectiveness studies of mental health interventions for adolescent with substance use disorder or problems of delinquency. The databases were consulted between 5 March 2013 and 8 March 2013. Additional studies were identified based on reference list search. There were no restrictions on the type of publication. The language of publication was required to be English 
and publication date was 1990 or more recent. The search strategy used is displayed below.

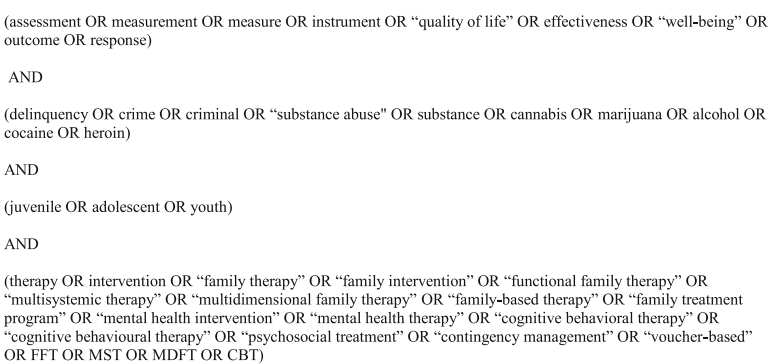

\section{Data analysis}

\section{Study selection}

First, duplicates were removed. Then, the study selection was performed in two rounds. First, a selection based on title and abstract was performed, then selected articles were subject to a second screening based on full texts. Both rounds of selection were performed by two researchers independently and were each followed by a round of consensus. The eligibility criteria for the first selection based on title and abstract were the following.

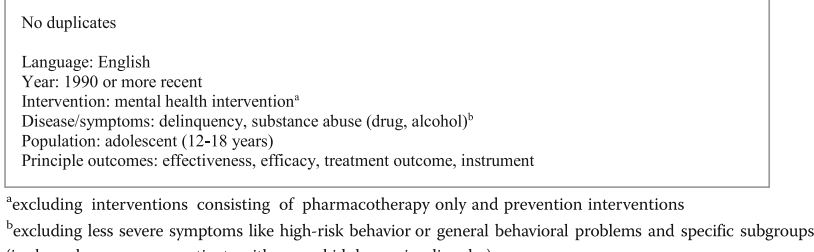

Subsequently, when abstracts or titles adhered to the above screening criteria, full texts were independently screened for inclusion based on the following (additional) criteria.

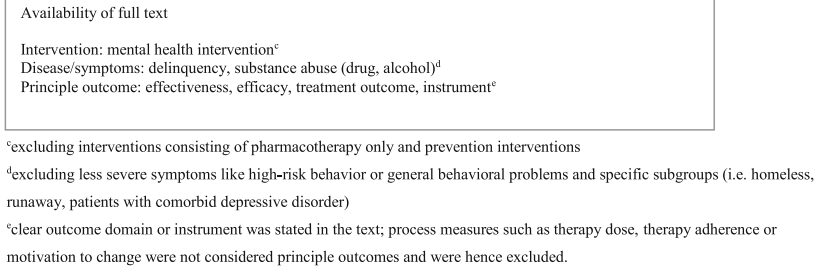

Furthermore, articles from reference lists of reviews were identified. For these, we performed a shortened screening and selection procedure. Titles of these articles were screened based on the following criteria: a) > =1990; b) peer-reviewed article; c) randomized control trial or effect/effectiveness/efficacy study/treatment outcome; d) adolescents; e) delinquency/ offenders/substance-abuse; f) mental health intervention (no pharmacotherapy). If this selection resulted in inclusion, the abstract was screened and a final decision on inclusion or exclusion was made. Included articles were added to the database of identified articles for further data synthesis.

\section{Data extraction}

Data extraction was performed in MS Access with predefined fields. From all selected studies, general information, such as the title of the study, the name of the author, journal, etc., were recorded, as well as information on the sample size, the studied population and type of intervention (systemic, other [i.e. individual, group intervention], both).

In addition to this general information, instrumentspecific information was extracted. This information consisted of instrument names (e.g. Child Behavior Checklist [CBCL]) and covered domains (e.g. family functioning, adolescent behavior, etc.). This information was recorded in order to identify the instruments currently used in the field and their coverage of the different systems relevant for the evaluation of systemic family interventions (Fig. 1).

\section{Synthesis and evaluation of results}

As a next step, domain names of the instruments were extracted from the identified articles and linked to the systems relevant for the evaluation of systemic family interventions (Fig. 1): youth, family, peers, school, work, society and neighbors. Domain names were verified with available resources such as guidelines, websites of the developer and other articles using the same instrument. After verification, the domains were translated into the systems mentioned in Fig. 1. For this purpose, domains related to the adolescents themselves, such as 'substance use and abuse,' 'physical health' or 'mental health' were linked to the system 'youth' whereas domains such as 'family relations' were recoded into the system 'family', domains like 'peer relations', 'social skills' or 'leisure/recreation' were labeled as 'peer' system, domains like 'educational status' were labeled 'school' and 'delinquency' as 'society'. Table 1 provides an example of the process of recoding for the Problem Oriented Screening Instrument for Teenagers (POSIT). Next, all instruments were classified based on the number of systems (presented in Fig. 1) covered and ranked from highest to lowest. Those covering five or more systems were considered most relevant for our purpose as those covered the majority of effects of systemic family interventions in adolescents with substance use disorder or problems of delinquency.

In line with our aim to identify an instrument, which captures most of the systems relevant to the evaluation of systemic family interventions, those instruments 
Table 1 Example of recoding of domains into systems

\begin{tabular}{ll}
\hline $\begin{array}{l}\text { Problem Oriented Screening Instrument for Teenagers (POSIT) } \\
\text { Domain }\end{array}$ & youth \\
\hline Substance use and abuse & youth \\
Physical health & youth \\
Mental health & family \\
Family relations & peers \\
Peer relations & school \\
Educational status & work \\
Vocational status & peers \\
Social skills & peers, \\
Leisure/recreation & society \\
Aggressive behavior/delinquency &
\end{tabular}

covering more than five systems were evaluated in more detail. These were then appraised according to necessarily arbitrary characteristics of brevity, feasibility, practicability, accessibility, psychometric properties and acceptance in the field. These characteristics were set up as to identify one or more instruments suitable to attain societal preferenceweights for an instrument by means of preferenceelicitation techniques. Within preference-elicitation techniques, such as discrete choice experiments, the number of domains rarely exceeds ten [28, 29]. With higher numbers of domains, the decision task may become too complex and cognitively demanding for the respondent [28]. Hence, a suitable instrument should possess less than 10 domains. A second consideration was the practical use of the instrument itself in clients. An instrument, ideally suitable for self-completion, should put as little strain as possible on the respondent, without loss of important content. Hence, we set a limit to the maximum number of items of the instrument at 500 and a maximum completion time of $1 \mathrm{~h}$, assuming that these would be reasonable amounts of items and time to ask from respondents. Another criterion was the accessibility of the instrument as to ascertain ease of use in future studies. Evaluation of this criterion included the price of use and availability of a (digital) version. Psychometric properties were considered to judge the suitability of the instrument for integration in health economic evaluations. Findings from existing publications on validity and reliability of the instruments were considered in this context. Finally, the frequency of use of the instrument was considered an indicator for the acceptance of the instrument in the clinical field. This was approximated by the number of times that an instrument was used in the studies identified in this review.

\section{Results}

\section{Study selection}

The systematic search resulted in 1060 articles. After duplicates were removed 1002 articles remained. Screening based on abstracts resulted in the exclusion of 880 articles. Full text assessment of the remaining 122 articles resulted in the exclusion of two articles not matching the definition of the intervention, 23 articles not matching the disease or symptoms of the target population, 13 not matching the requirements for the principle outcome of the studies, and 9 due to unavailability of a full text version. Hence 75 articles were included. Furthermore, 318 underlying articles from reviews were screened. From these, 166 articles remained after duplications with the first search results were removed. The screening of these articles in a first round by title and in a second round by title and abstract resulted in the exclusion of 161 articles and inclusion of five additional publications (Fig. 2).

\section{Study results}

A total of 80 articles were included in the synthesis. The aim was to identify clinical instruments in the field suitable for integration in a health-economic framework based on criteria of coverage of relevant systems, feasibility to perform preference-elicitation techniques, practicability of use, accessibility for future studies, psychometric properties and acceptance in the field. A summary of the identified reviews and clinical trials is provided in Tables 2 and 3 respectively. From the 80 selected articles we identified a total of 102 instruments, differing substantially in what these intended to measure and in whom. These instruments measured varying (combinations of) outcomes such as substance use, physical health, mental health, family relations, peer relations, school and work status and criminal history.

\section{Instrument suitability for evaluation of systemic family interventions}

Table 4 displays the instruments ranked according to the number of systems covered.

The majority, 81 instruments, covered just one system such as the youth or the family system. These onedimensional instruments were often used in a multimethod (i.e. a combination of self-report, parent-report, court records, urine-analysis, etc.) assessment battery of instruments. Fourteen instruments covered two, three or four systems. We identified eight instruments, which covered five or more systems and which therefore were considered potentially suitable for comprehensive evaluation of systemic family interventions.

Detailed information on these eight instruments was searched and is highlighted below. It has to be noted that available information per instrument (e.g. number of items, example questions, domain names, most recent versions of the instrument, type of administration, etc.) strongly differed.

The Adolescent Drug Abuse Diagnosis (ADAD) [30] is a multidimensional instrument to evaluate adolescent 


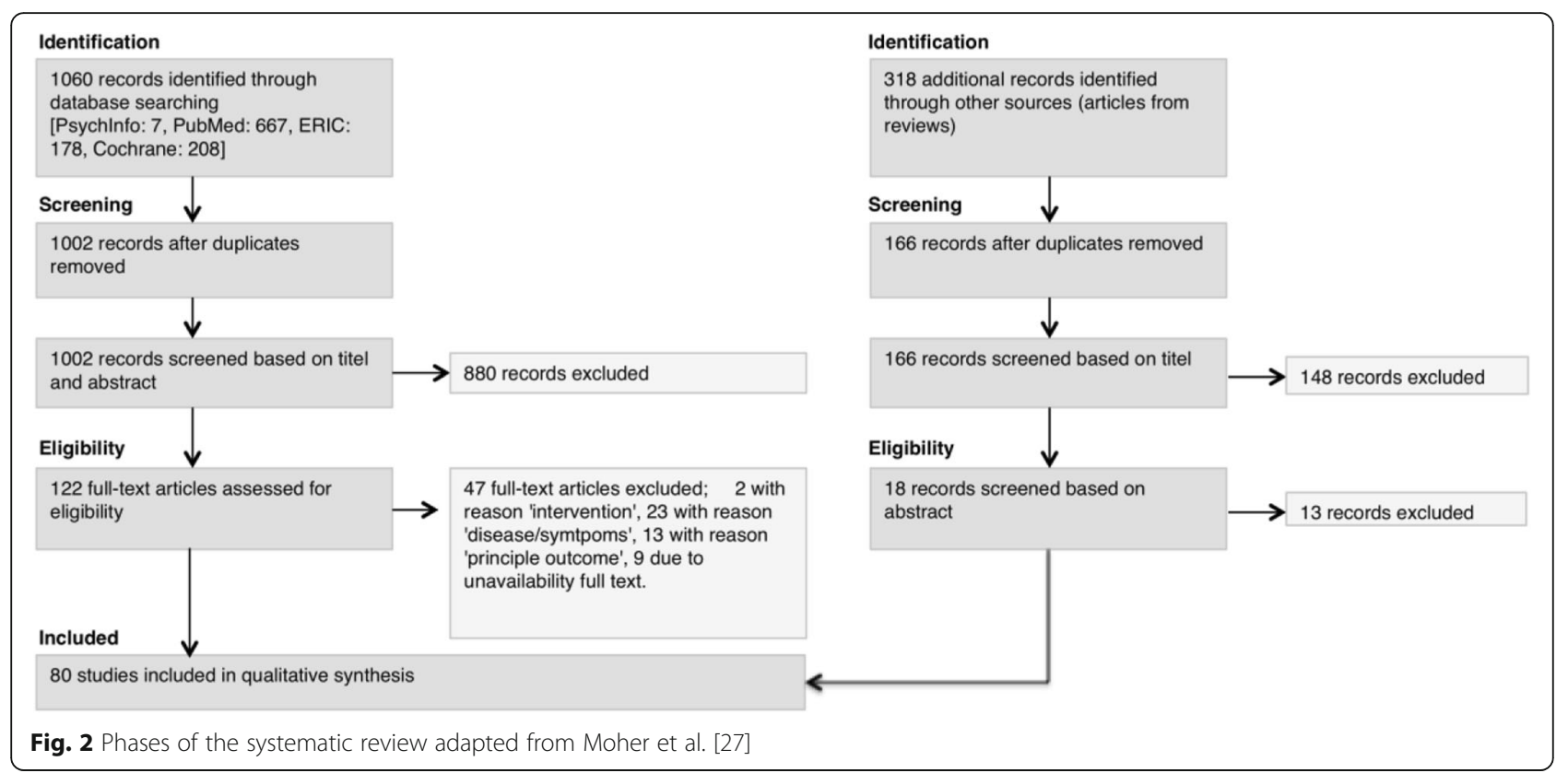

substance use [31] administered in a structured interview. It covers nine problem areas: medical, school, employment, social relations, family and background relations, psychological, legal, alcohol use, and drug use [32]. Example questions are "How would you rate your overall physical health?", "How many days in the past 30 have you been absent (from school)?" and "How many months did you work fulltime in the past six months?". A patient's treatment need is assessed by the interviewer per problem area based on a 10-point rating scale with scores $0-1$ (no real

Table 2 List of identified reviews

\begin{tabular}{|c|c|c|c|}
\hline ID & Authors & Year & Population \\
\hline 1 & Armelius Bengt-Åke, Andreassen Tore Henning & 2007 & youth with antisocial behavior \\
\hline 2 & Baldwin SA, Christian S, Berkeljon A, Shadish WR. & 2011 & adolescent delinquents and substance-abusers \\
\hline 3 & Borduin CM. & 1999 & criminal and violent adolescents \\
\hline 4 & Brown SA, D'Amico EJ. & 2003 & adolescent substance abusers \\
\hline 5 & Cottrell D, Boston P. & 2002 & patients with conduct and attention deficit disorders, substance misuse, etc. \\
\hline 6 & Curtis N, Ronan K, Borduin C M & 2004 & antisocial youths and youths with serious emotional disturbances \\
\hline 7 & Deas D, Thomas SE. & 2001 & adolescents with substance use disorders \\
\hline 8 & Deas D. & 2007 & adolescents with $\mathrm{AOD}$ disorders \\
\hline 9 & Diamond G, Josephson A. & 2005 & adolescent substance use \\
\hline 10 & Ferguson LM, Wormith JS. & 2012 & (adult and) young offenders \\
\hline 11 & Henggeler SW, Sheidow AJ. & 2012 & conduct disorder and delinquency in adolescents \\
\hline 12 & Henggeler SW, Sheidow AJ. & 2003 & conduct disorder and delinquency in adolescents \\
\hline 13 & Hogue A, Liddle HA. & 2009 & adolescent substance abuse \\
\hline 14 & Littell Julia H, Campbell Margo, Green Stacy, Toews Barbara & 2005 & (among others) delinquent youth \\
\hline 15 & Randall J, Cunningham PB. & 2003 & violent substance-abusing and substance-dependent juvenile offenders \\
\hline 16 & Tanner-Smith EE, Wilson SJ, Lipsey MW. & 2013 & adolescent substance use disorder \\
\hline 17 & Tripodi SJ, Bender K, Litschge C, Vaughn MG. & 2010 & adolescent alcohol use \\
\hline 18 & Waldron HB, Kaminer Y. & 2004 & adolescent substance use disorders \\
\hline 19 & Waldron $\mathrm{HB}$, Turner CW. & 2008 & adolescent substance abuse \\
\hline 20 & Walker D F, McGovern S K, Poey E L, Otis K E & 2004 & adolescent sexual offenders \\
\hline 21 & Woolfenden Susan, Williams Katrina J, Peat Jennifer & 2001 & adolescents with delinquency or conduct disorder \\
\hline
\end{tabular}




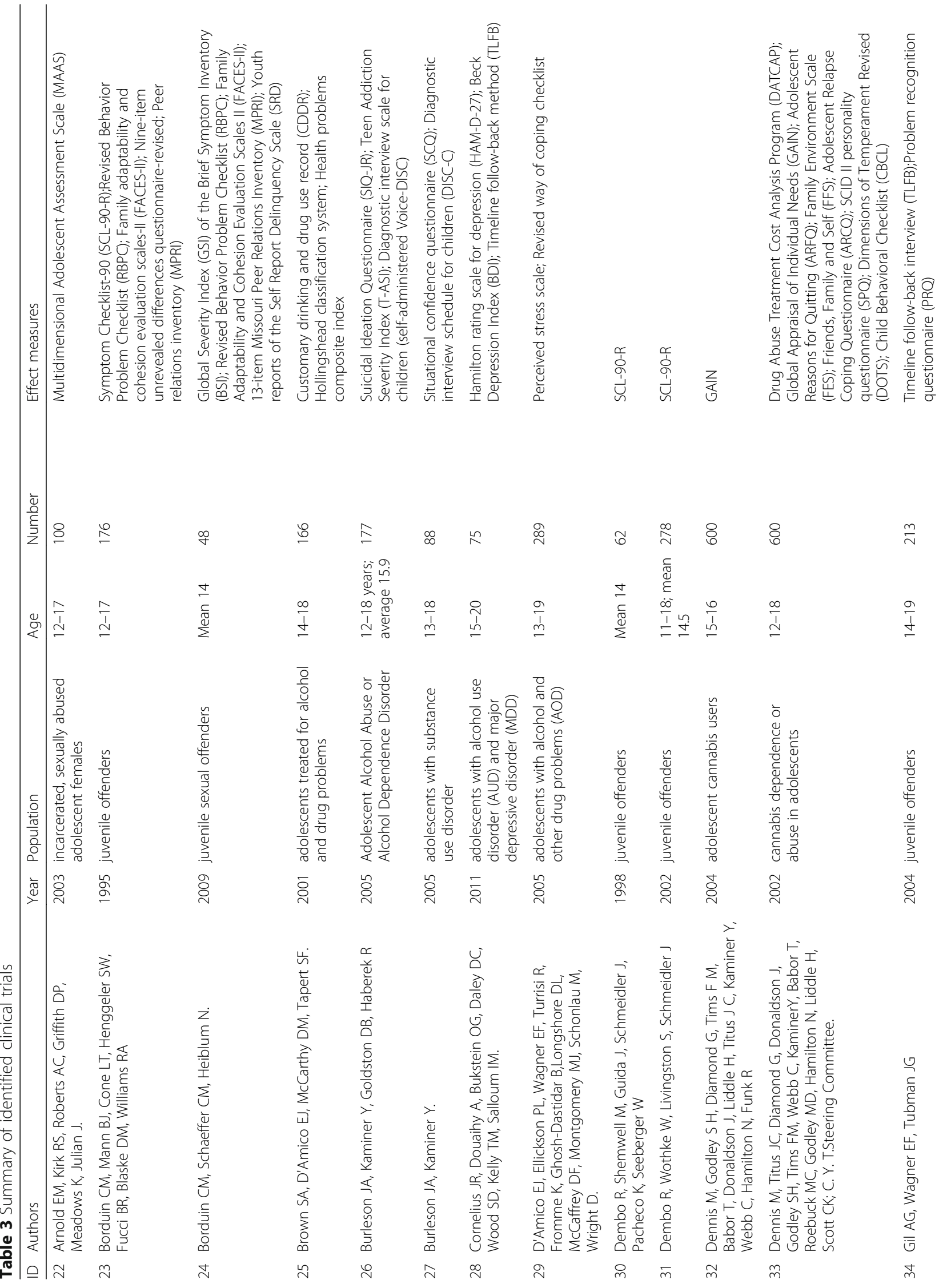




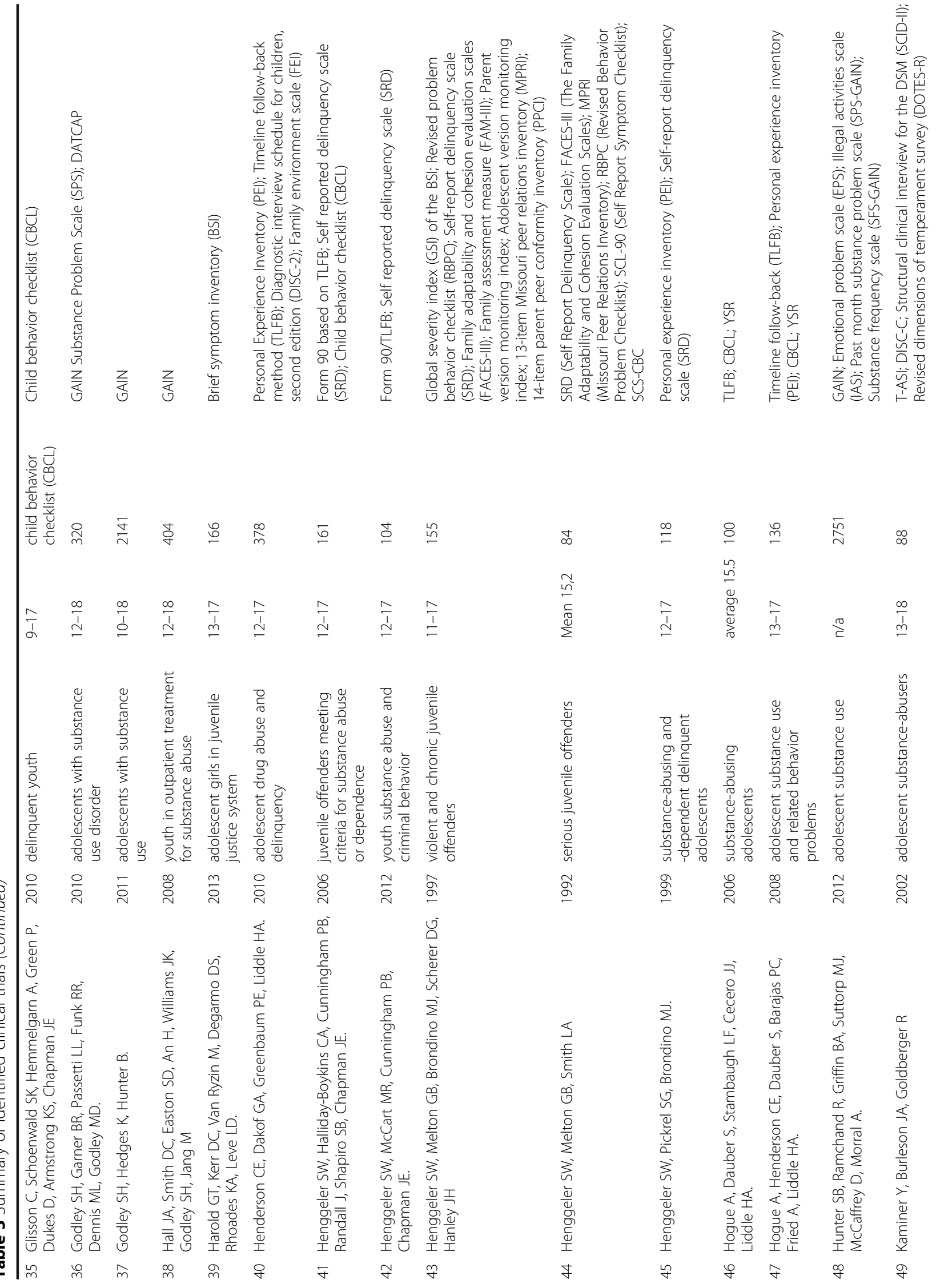




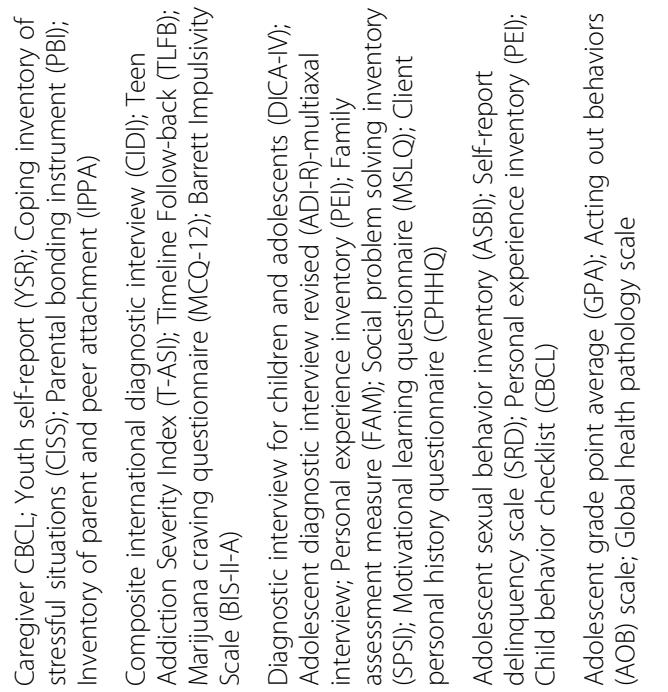

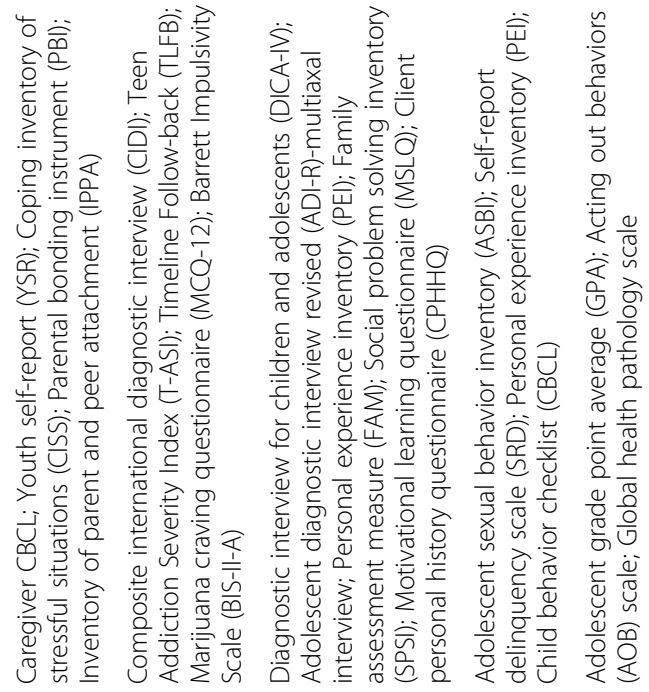

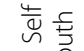

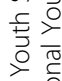

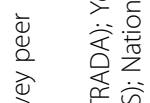

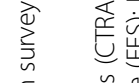

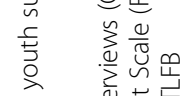

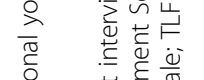

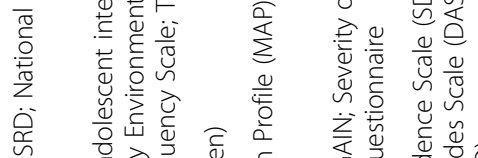

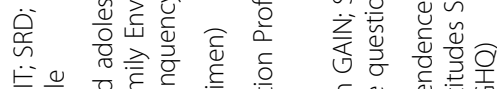

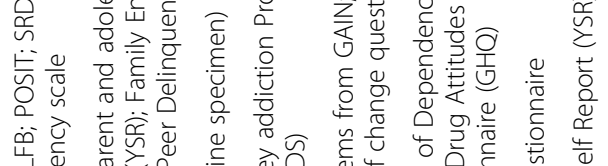

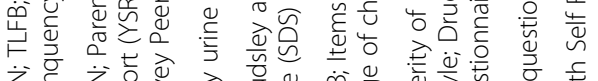

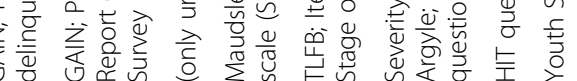

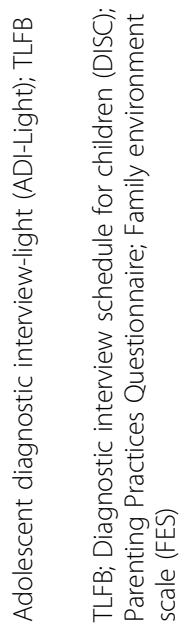
$\infty \quad \bar{m}$
$\stackrel{\Upsilon}{+}$

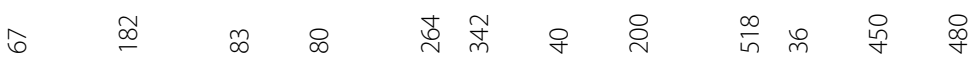

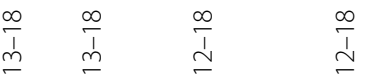

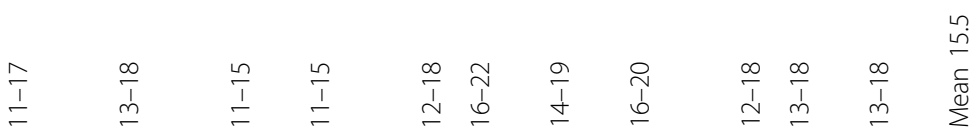
空

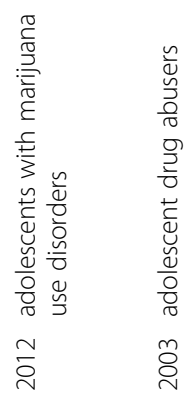

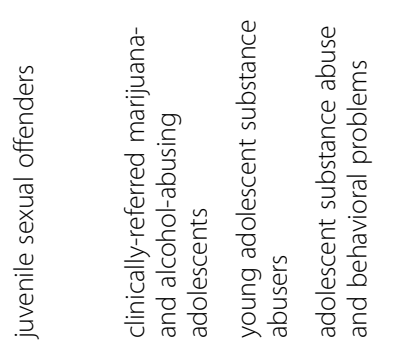

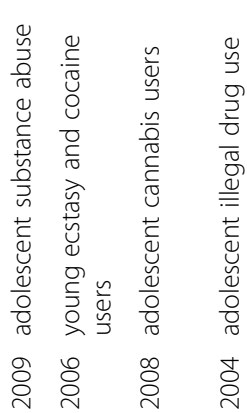

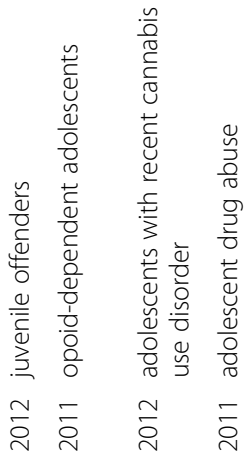
ळे
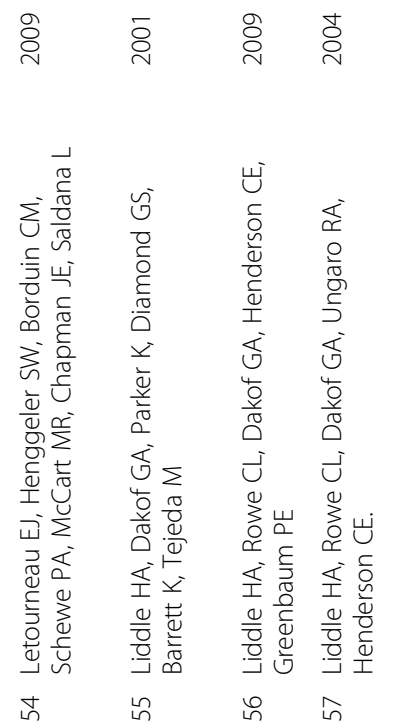

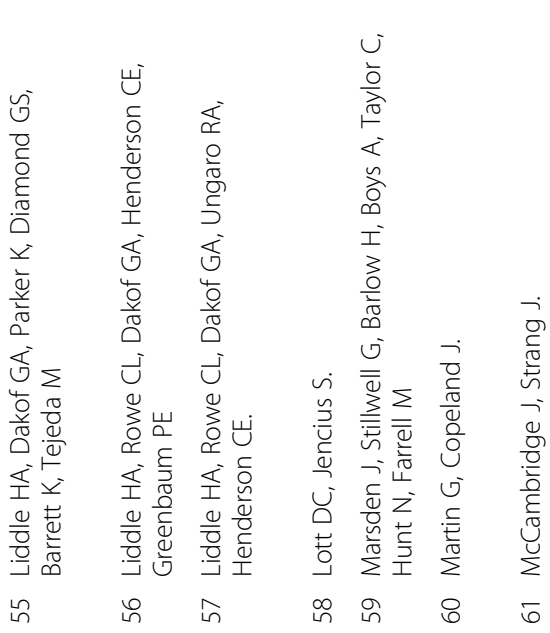

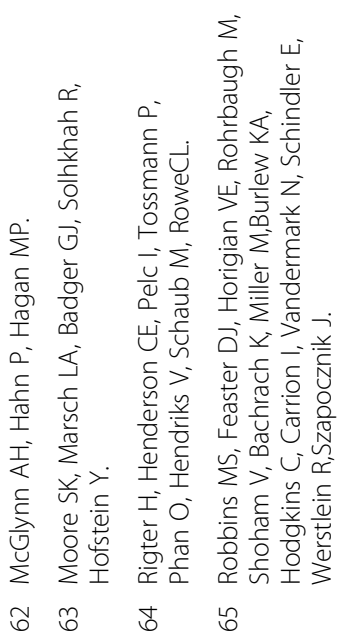




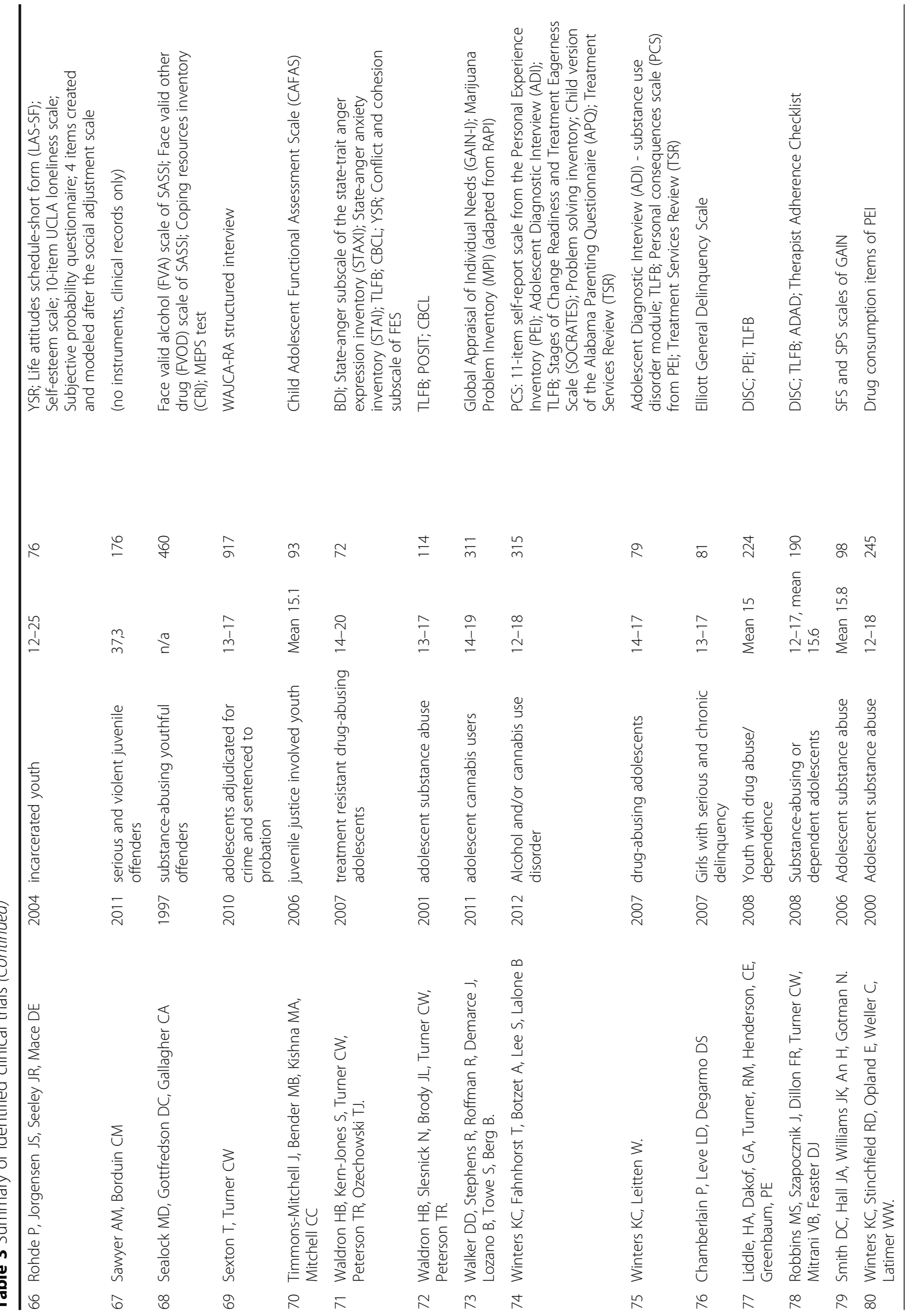


Table 4 Ranking of instruments according to the number of systems covered

\begin{tabular}{|c|c|c|c|c|c|c|c|c|}
\hline \multirow[t]{2}{*}{ Name instrument } & \multirow[t]{2}{*}{ \# systems covered } & \multicolumn{7}{|c|}{ Systems } \\
\hline & & youth & family & peers & school & work & society & neighbors \\
\hline POSIT & 6 & $\bullet$ & $\bullet$ & $\bullet$ & $\bullet$ & $\bullet$ & $\bullet$ & \\
\hline CAFAS & 6 & $\bullet$ & $\bullet$ & $\bullet$ & $\bullet$ & $\bullet$ & $\bullet$ & \\
\hline WAJCA-RA & 6 & $\bullet$ & $\bullet$ & $\bullet$ & $\bullet$ & $\bullet$ & $\bullet$ & \\
\hline ADAD & 6 & $\bullet$ & $\bullet$ & $\bullet$ & $\bullet$ & $\bullet$ & $\bullet$ & \\
\hline T-ASI & 6 & $\bullet$ & $\bullet$ & $\bullet$ & $\bullet$ & $\bullet$ & $\bullet$ & \\
\hline CTRADA & 5 & $\bullet$ & $\bullet$ & $\bullet$ & $\bullet$ & & $\bullet$ & \\
\hline$A D I$ & 5 & $\bullet$ & $\bullet$ & $\bullet$ & $\bullet$ & & $\bullet$ & \\
\hline GAIN & 5 & $\bullet$ & $\bullet$ & & $\bullet$ & $\bullet$ & $\bullet$ & \\
\hline PEI & 4 & $\bullet$ & $\bullet$ & $\bullet$ & $\bullet$ & & & \\
\hline MAAS & 4 & $\bullet$ & $\bullet$ & $\bullet$ & $\bullet$ & & & \\
\hline FES & 4 & $\bullet$ & $\bullet$ & $\bullet$ & $\bullet$ & & & \\
\hline $\mathrm{CPHHQ}$ & 3 & & & $\bullet$ & $\bullet$ & & & $\bullet$ \\
\hline FFS & 3 & $\bullet$ & $\bullet$ & $\bullet$ & & & & \\
\hline SCQ & 3 & $\bullet$ & & $\bullet$ & & $\bullet$ & & \\
\hline SRD & 2 & $\bullet$ & & & & & $\bullet$ & \\
\hline SCL-90-R & 2 & $\bullet$ & $\bullet$ & & & & & \\
\hline $\mathrm{BSI}$ & 2 & $\bullet$ & $\bullet$ & & & & & \\
\hline Hollinghead classification system & 2 & & & & $\bullet$ & $\bullet$ & & \\
\hline IPPA & 2 & & $\bullet$ & $\bullet$ & & & & \\
\hline CRI & 2 & $\bullet$ & $\bullet$ & & & & & \\
\hline MAP & 2 & $\bullet$ & & $\bullet$ & & & & \\
\hline
\end{tabular}

Note. $\cdot=$ system covered by instrument

problem), 2-3 (slight problem, treatment probably not necessary), 4-5 (moderate problem, some treatment indication), 6-7 (considerable problem, treatment necessary), and 8-9 (extreme problem, treatment absolutely necessary) [32]. The instrument consists of 150 items and is based on the Addiction Severity Index (ASI) [24]. There is also a European version of the instrument, the European Adolescent Assessment Dialogue (EuroADAD). Its aim is to "describe, communicate and compare young clients over borders of countries and institutions." [33].

The Adolescent Diagnostic Interview (ADI) [34] originated in the 1980's as a project "to address measurement gaps in the alcohol-drug field" [35]. It is a tool to measure substance use disorders in adolescents "...organized around $D S M-I I I-R$ criteria for psychoactive substance use disorders." [34]. In the literature a version based on DSM-IV criteria is also mentioned [36]. The instrument is administered in a structural interview setting. Substance use of the adolescent is assessed based on two main sections with each two subsections: clinical (sociodemographics, psychosocial stressors, substance use frequency and duration, alcohol symptoms, cannabis symptoms, other substance symptoms and level functioning) and appendix (orientation and memory screen)
[34]. Example items are "Which drugs have you used five or more times in your life?", "How many times do you think that you have used (this drug/each drug) in the past 6 months?", "Have you ever continuously felt like crying for several days in a row?" [36]. A computerbased version is available for self-assessment [34].

The Child Adolescent Functional Assessment Scale (CAFAS) “....assesses the degree of impairment in functioning in children and adolescents secondary to emotional, behavioral, or substance use problems" [37]. The instrument originally included seven scales, of which five evaluated the functioning of the youth and two scales assessed the environment of the youth [37]. The five youth scales were role performance, thinking, behavior towards self and others, moods/emotions, and substance use [37]. The two environment scales were basic needs and family/social support. The scales subsequently have been changed and expanded to 8 youth and 2 caregiver scales: school, home, community, behavior towards others, moods, self-harm, substance use, and thinking (youth) and material needs, and social support (caregiver) [38]. The different subscales include items of four severity levels (i.e. severe, moderate, mild, and minimal or no impairment) [37]. The assessor determines the level of 
problems of the patient per subscale. He first considers the items of the most severe level, checks whether these items apply and if not progresses towards the lesser symptom levels until an item of the current severity level applies to the patient [37]. Then scores of 30, 20, 10 and 0 are applied to severity levels severe, moderate, mild and minimal respectively such that an overall severity rating is generated. Overall ratings range from 0 to 240 with higher scores indicating higher severity [30].

The Global Appraisal of Individual Needs (GAIN) questionnaire [39] is a collection of related instruments that are gathered under the umbrella of GAIN using an identical format. The most recent version of the questionnaire has been adapted for use in adults as well as adolescents. The GAIN is an assessment measure, which can be used in several settings and populations such as inpatient, outpatient short- or long-term treatment evaluation, legal programs or school-based programs [40]. It assesses eight domains: background, substance use, physical health, risk behaviors, mental health, environment, legal, and vocational. Example items of the GAIN are "During the past 90 days, on how many days were you in foster care?", "When was the last time, if ever, you used...any kind of alcohol?", and "What was the most (drinks/joints/etc.) you had in one day?" [41].

The Problem Oriented Screening Instrument for Teenagers (POSIT) is a screening instrument for adolescents with substance use disorder, which was designed as a component of the Adolescent Assessment/Referral System (AARS) [42]. It "is designed to flag those functional areas, if any, where a problem MAY exist that requires further assessment and perhaps treatment." [42]. The instrument addresses ten functional domains: substance use/abuse, physical health status, mental health status, family relations, peer relations, educational status, vocational status, social skills, leisure and recreation, and aggressive behavior and delinquency. The POSIT includes 139 items, which can be answered with yes or no [42]. Per domain, items can be grouped into three categories: general purpose items, general purpose age-related items, and red flag items [42]. Each affirmative response to a general purpose item counts as one point towards the total functional domain score [42]. The same holds for general purpose age-related items, but these are only relevant for specific age groups of respondents (below or above 16 years) [42]. Red flag items indicate the need for treatment once one of these items is answered positively [42]. Example items of the POSIT are "Do you get into trouble because you use drugs or alcohol at school?", "Do your parents or guardians argue a lot?", and "Have you ever been told you are hyperactive?" [42].

The Teen Addiction Severity Index (T-ASI) [43] is the adolescent version of the ASI [24]. The instrument assesses seven dimensions of functioning (i.e. alcohol and drug use, school status, employment-support status, family relationships, legal status, peer-social relationships, and psychiatric status) [43]. The T-ASI is intended for use in adolescents with substance use disorder aged between 12 and 19 years [43]. Example items of the TASI are "What chemicals have you used in the past month?", "School days spent in detention or any other measures taken for disciplinary reasons last month. (Principal's or school counselor's office.)", and "How long was your longest period of employment during the past year?" [44]. Responses are rated on a 5-point scale [43]. A revised version of the T-ASI, the T-ASI-2 has been developed in 2008. This concerns a version of the instrument, which is self-administered via computer or telephone and contains additional domains [45].

The WAJCA-RA structured interview is a risk assessment tool for juvenile offenders developed by the Washington State Institute for Public Policy in collaboration with the juvenile courts [46]. It was designed to identify risk and protective factors in the following domains: criminal history, school, use of free time, employment, relationships, family, alcohol and drugs, mental health, attitudes, social skills, progress on community supervision, progress while confined [46]. Example items of the WAJCA-RA are "Violence/anger: Reports of displaying a weapon, fighting, threatening people, violent outbursts, violent temper, fire starting, animal cruelty, destructiveness, volatility, intense reactions.", "Runaways or times kicked out of home", and "Number of weeks of longest period of employment" [46].

The Parent and adolescent interview CTRADA that was used by Liddle et al. [47] was not considered a common instrument but institution-specific interview as no references could be retrieved from neither literature nor the Internet. The instrument therefore could not be further considered or assessed.

\section{Instrument suitability for use in CUA}

Hence seven instruments remained for further consideration. The frequency of use of each of these instruments in the identified studies is presented in Table 5. Furthermore, Table 6 illustrates an evaluation of the instruments for suitability for use in CUA and use of preference elicitation techniques. When our feasibility characteristics were applied to the seven instruments, three instruments (POSIT, WAJCA, ADI) were excluded due to the number of domains exceeding ten, and one instrument (GAIN) was excluded due to reasons of practicability (i.e. number of items exceeding the maximum of 500 and completing time exceeding $1 \mathrm{~h}$ ). It was noted that a short version of the GAIN (Global Appraisal of Individual Needs Short Screener, GAIN-SS) is available as well [48]. However, based on its goals of screening, use for clinical staff with limited experience or periodic measurement [48], this instrument is considered too restricted for the purpose of 
Table 5 Frequency of instrument use

\begin{tabular}{ll}
\hline Instrument name & $\begin{array}{l}\text { \# of papers which } \\
\text { used this measure }\end{array}$ \\
\hline Global Appraisal of Individual Needs (GAIN) & 13 \\
Teen Addiction Severity Index (T-ASI) & 4 \\
Adolescent Diagnostic Interview (ADI) & 4 \\
$\begin{array}{l}\text { Problem Oriented Screening Instrument } \\
\text { for Teenagers (POSIT) }\end{array}$ & 2 \\
$\begin{array}{l}\text { Child Adolescent Functional Assessment } \\
\text { Scale (CAFAS) } \\
\text { Washington Association of Juvenile } \\
\begin{array}{l}\text { Court 6Administrators - Risk Assessment } \\
\text { (WAJCA-RA) }\end{array} \\
\text { Adolescent Drug Abuse Diagnosis (Euro-ADAD) }\end{array}$ \\
\hline
\end{tabular}

this study. The remaining three instruments (CAFAS, T-ASI and Euro-ADAD) were considered candidates for use in CUA. One instrument (CAFAS) was considered slightly less suitable due to reasons of accessibility (i.e. concerning a paid instrument as opposed to freely available online versions of other instruments). For the remaining two instruments (T-ASI and the Euro-ADAD) only limited information on psychometric properties could be obtained. It needs noting that the T-ASI and Euro-ADAD are related as they are both based on the ASI adult instrument $[33,43]$. Psychometric properties of this 'predecessor' have been judged satisfactory [24, 49-52]. To our knowledge Euro-ADAD is more frequently used in Europe, whereas T-ASI is more commonly used in the United States.

Two psychometric studies with small sample sizes were identified for the T-ASI $[43,53]$ and one study [33] with a larger sample size was identified for the Euro-ADAD. Frequency of use was slightly favorable for the T-ASI compared to the Euro-ADAD as the instrument was used four times in the studies identified in this systematic review, whereas the Euro-ADAD was used in no more than one study. These differences were not considered sufficient to justify favoring either of the instruments over the other. Hence, the T-ASI and Euro-ADAD were considered to have equal potential suitability for the comprehensive evaluation of systemic family interventions in a health economic framework.

\section{Discussion and conclusions}

The objective of this systematic literature review was to identify existing instruments in the field of adolescent delinquency and substance use, which cover the relevant domains of systemic family interventions. The instruments were appraised based on characteristics relevant for use in economic evaluations such as brevity, accessibility, psychometric properties etc. Euro-ADAD and T-ASI showed favorable characteristics in relation to the criteria for a comprehensive outcome measure, covering multiple relevant systems and being suitable for obtaining preference weights. Both instruments lack preference weights for the outcomes, at present. Attaining these (as a potential next step) would facilitate calculating 'utility scores' as common in economic evaluations. Furthermore, the results of the current study may inform future efforts towards standardized and comprehensive core outcome sets as defined by the COMET initiative [54]. The study may be seen as a preparatory step towards a full COMET effort to standardizing the QALY approach to include broader effects.

Some limitations of this study must be noted. First, given our focus on published research up to 2013, we may have missed out on very recent developments in this field. In the Netherlands, for instance, a new, comprehensive instrument for measuring substance abuse in adolescents is being developed, called the MATE-Y [55], which includes nine modules each containing several domains. Yet, up to today there have not yet been publications on the MATE in the field of youth/adolescents. But similar developments may be ongoing elsewhere. Second, we have not investigated the possibility of constructing a new measure by combining different measures into one composite measure. Though this may be a limitation of this paper, we considered it a necessary first step to identify the instruments currently available in the field for direct use. This may also help to highlight the relevant domains to include in a newly developed instrument. With our approach, we were able to identify two instruments as most promising candidates to use in comprehensive evaluations of systemic family interventions. Neither instrument is currently considered gold standard' in practice. Furthermore, as common for systematic reviews, the results from the current study are based on a limited selection of databases within a limited timeframe. Yet the number of screened and identified articles was extensive and we assume that the consultation of an even larger number of databases would not have yielded significant differences in results. Also, the characteristics for further selection of the instruments were necessarily arbitrary and guided by our goal of selecting one or more instruments suitable to be used to attain societal preference weights and be used in economic evaluations in the long term. We realize that the suitability criterion of a maximum of 500 questions/ $1 \mathrm{~h}$ of completion time may be rather high when considering the busy clinical practice and ongoing evaluation of patient progress. Furthermore, had we considered different or more broad characteristics, additional instruments might have been found suitable. For example, one could think of shortening existing longer instruments first and then proceeding towards steps of attaining societal preference weights. In the light of limited time, this was not considered feasible in the current study. 


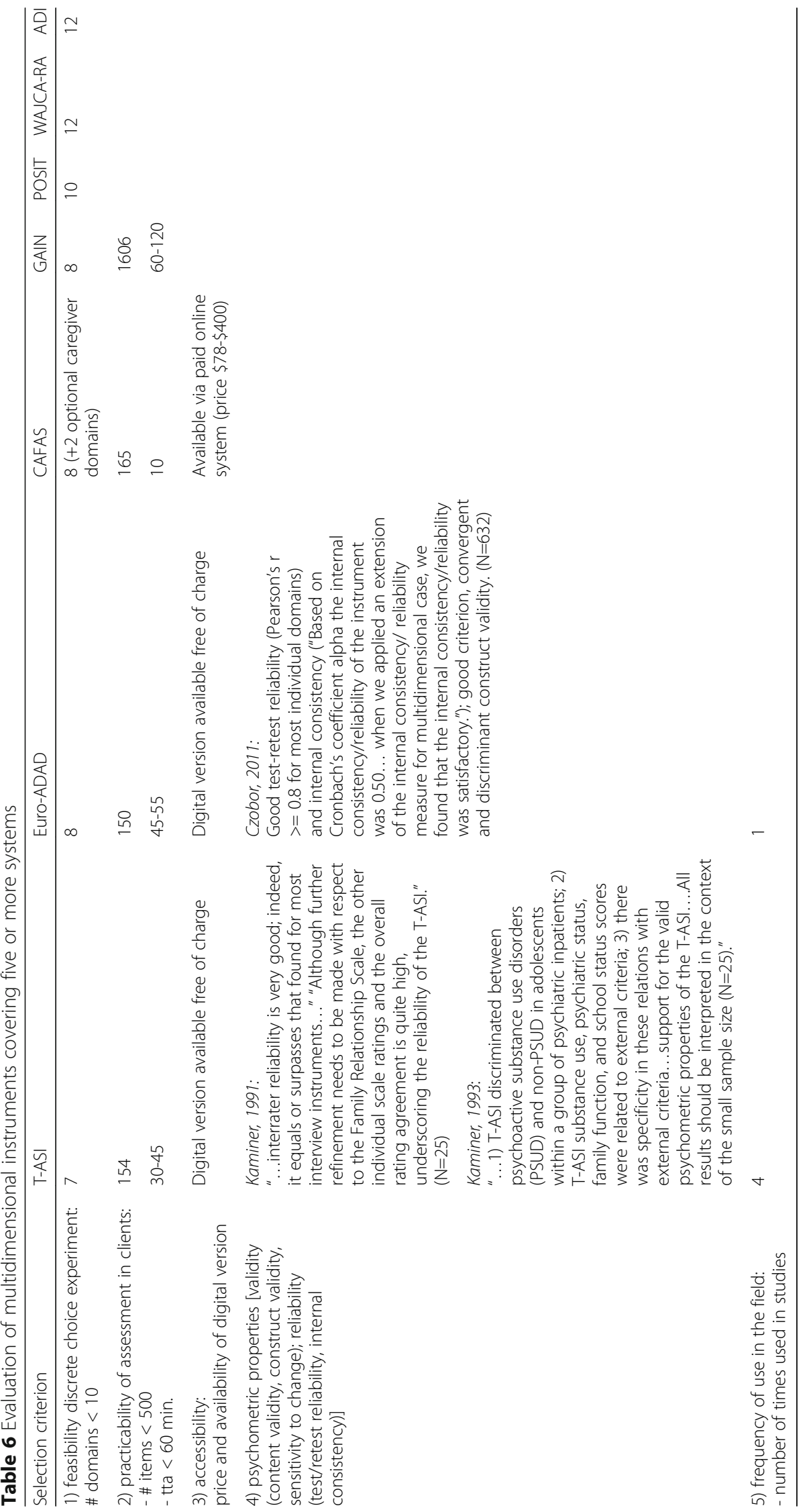


Notwithstanding these limitations, our review revealed two promising, currently used instruments, which may be made suitable for inclusion in economic evaluations of systemic family interventions: the Euro-ADAD and T-ASI. To make these instruments suitable for health economic evaluations, first of all, more detailed investigation is necessary of their validity, feasibility and comprehensiveness. Current information on this is scarce, yet needed. Moreover, using these instruments in health economic evaluations will require important next steps. In particular, preference weights would need to be derived for the different states described by the instrument, like those available for health-related utility measures such as the EQ-5D. This is possible through preference elicitation techniques, such as discrete choice experiments or time-trade-off techniques, ultimately leading to 'utility scores', which can be attached to the different 'states' described by the instrument.

Intriguing questions in this context relate to who should indicate the state a person is in and who should provide the values for the different possible states (i.e., whose preferences count). In line with many guidelines for health-economic evaluations $[11,56]$, and in line with the broad aim of systemic family interventions, one could ask 'patients' to provide self-reports based on one of the identified multidimensional instruments. The value attached to this state could then be based on preferences obtained in the general population. This would provide 'societal weights' for the broad outcomes of systemic family interventions. These societal weights could thus be attached to the state a person indicates him- or herself to be in on the multidimensional instrument, thus leading to an overall utility score. Given the broad range of outcomes, including effects incurred by others than the patient or even his family (e.g., a safe neighborhood), the score thus relates to a preference ordering over states that include the effects on more than the patient alone. This may be an additional reason for opting for general public preferences. However, whether the general public is the appropriate source (rather than e.g. decision makers or health care professionals) must be further assessed and discussed, as well as their ability to appropriately weight such diverse outcomes. The more fundamental question is whether these scores would count as 'utilities' or rather as multi-criteria decision weights.

Other relevant issues in developing a multidimensional utility measure of systemic family interventions may be the diversity and hierarchy of treatment effects. As mentioned earlier, a comprehensive measure would include health as well as non-health effects and would also include both the effects on the patient himself and society as a whole. Obviously, these different effects may be interrelated. Moreover, some observable effects may be considered to be intermediate effects, whereas others may be final outcomes. Related to this point, there may be short-term and longterm effects, which can be important. Hence, in the construction of such a preference-based measure, good care needs to be taken of the possible interaction of the effects.

One may argue that an alternative route to finding an appropriate outcome measure could be to use existing measures in the field of economic evaluation, most notably QALY measures. To our knowledge, so far there have been only a few studies on the validity of preference-weighted health-related quality of life instruments in an adult population of substance abusers $[57,58]$. There have been two studies on the degree to which common preference-weighted measures of quality of life (e.g. QWB-SA, SF-12) correlate with substance use severity $[58,59]$. Whereas the first study provides evidence for insufficient coverage of all disease dimensions in substance use disorder [58], the second study does suggest moderate to good correlation between quality of life measures and substance use severity measures [59]. In order to verify these results and determine whether the proposed instruments add value in the field of delinquency and substance abuse in adolescents, further research on the suitability and potential of the quality adjusted life year (QALY) measure in this population is recommended.

Keeping these alternatives in mind, further research on the instruments highlighted in the current paper, specifically on the attachment of societal preference weights could bring evaluation of mental health interventions for delinquent and substance abusing adolescents closer to the standard methodology in health economic evaluations of curative medical interventions. Both identified instruments appear suitable and broad enough to capture the effects of family interventions in substance abusing and delinquent adolescents in such CUA. Adding societal preference weights to one of these instruments will create an instrument, which combines the advantage of the specificity of a disorderspecific instrument with compliance with common methodology of health economic evaluations and captures the broad effects relevant to mental health interventions. CUAs of these interventions can then be performed based on a broad and specific measure that includes several systems/dimensions and at the same time acknowledges the relative value that society attaches to improvements in these diverse systems. Though performing CUAs in the field of substance abuse and delinquency in adolescents remains a challenging task, this paper attempted to contribute to confronting one of the major issues in that context: finding a suitable outcome measure. 


\section{Abbreviations}

AARS: Adolescent Assessment/Referral System; ADAD: Adolescent Drug Abuse Diagnosis; ADI: Adolescent Diagnostic Interview; ASI: Addiction Severity Index; BSFT: Brief Strategic Family Therapy; CAFAS: Child Adolescent Functional Assessment Scale; CBCL: Child Behavior Checklist; CBT: Cognitive Behavioral Therapy; CUA: Cost-utility analysis; EBFT: Ecologically Based Family Therapy; ERIC: Education Resource Information Center; EuroADAD: European Adolescent Assessment Dialogue; FFT: Functional Family Therapy; GAIN: Global Appraisal of Individual Needs; GAIN-SS: Global Appraisal of Individual Needs Short Screener; MDFT: Multidimensional Family Therapy; MET: Motivational Enhancement Therapy; MST: Multisystemic Therapy; POSIT: Problem Oriented Screening Instrument for Teenagers; QALYs: Quality-Adjusted Life-Years

\section{Acknowledgements}

The authors would like to thank Maartje Goorden for her assistance in screening the publications.

\section{Availability of data and materia}

The datasets used and/or analyzed during the current study are available from the corresponding author on reasonable request.

\section{Funding}

The study was conducted with a grant from the Netherlands organization for health research and development (ZonMw), The Hague. The funding organization had no role in the in the design of the study and collection, analysis, and interpretation of data and in writing the manuscript.

\section{Authors' contributions}

CB was involved in the screening of the articles and the review of all versions of the manuscript. LH was involved in the overall design of the study, the formulation of selection criteria and suitability characteristics, review of all versions of the manuscript and program supervision. ES, VC and WB acted as advisors to the study and reviewed all versions of the manuscript. SS was involved in the overall design of the study, the screening of the articles, the formulation of selection criteria and suitability characteristics and writing the manuscript. All authors approved the final version of the manuscript.

\section{Ethics approval and consent to participate}

Not applicable.

\section{Consent for publication}

Not applicable.

\section{Competing interests}

Clazien Bouwmans (CB), Werner Brouwer (WB) and Leona Hakkaart (LH) declare to have no competing interests. Saskia Schawo (SS), Evelien van der Schee (ES) and Vincent Hendriks (VH) are employees of Parnassia Groep, a Dutch mental health institution, which among others offers systemic interventions to its clients.

\section{Publisher's Note}

Springer Nature remains neutral with regard to jurisdictional claims in published maps and institutional affiliations.

\section{Author details}

'Institute for Medical Technology Assessment \& Institute of Health Policy \& Management, Erasmus University Rotterdam, P.O. Box 1738, 3000 DR Rotterdam, The Netherlands. ${ }^{2}$ Parnassia Addiction Research Centre (PARC), Brijder Addiction Treatment, Parnassia Bavo Group, Monsterseweg 83, 2553 RJ The Hague, The Netherlands. ${ }^{3}$ Curium, Leiden University Medical Centre, Department of Child and Adolescent Psychiatry, Leiden University, Leiden, The Netherlands.

Received: 12 February 2017 Accepted: 17 July 2017

Published online: 19 September 2017

\section{References}

1. Cottrell D, Boston P. Practitioner review: The effectiveness of systemic family therapy for children and adolescents. J Child Psychol Psychiatry. 2002;43(5):573-86
2. Randall J, Cunningham PB. Multisystemic therapy: a treatment for violent substance-abusing and substance-dependent juvenile offenders. Addict Behav. 2003;28(9):1731-9.

3. Brysbaert M. Psychologie. Gent: Academia Press; 2009.

4. Hendriks V, van der Schee E, Blanken P. Treatment of adolescents with a cannabis use disorder: main findings of a randomized controlled trial comparing multidimensional family therapy and cognitive behavioral therapy in The Netherlands. Drug Alcohol Depend. 2011;119:64-71.

5. Henggeler SW, Sheidow AJ. Empirically supported family-based treatments for conduct disorder and delinquency in adolescents. J Marital Fam Ther. 2002;38(1):30-58.

6. French MT, Zavala SK, McCollister KE, Waldron HB, Turner CW, Ozechowski TJ. Cost-effectiveness analysis of four interventions for adolescents with a substance use disorder. J Subst Abus Treat. 2008;34(3):272-81.

7. Borduin CM, Mann BJ, Cone LT, Henggeler SW, Fucci BR, Blaske DM, et al. Multisystemic treatment of serious juvenile offenders: long-term prevention of criminality and violence. J Consult Clin Psychol. 1995:63(4):569-78.

8. Henggeler SW, Clingempeel WG, Brondino MJ, Pickrel SG. Four-year follow-up of multisystemic therapy with substance-abusing and substance-dependent juvenile offenders. J Am Acad Child Adolesc Psychiatry. 2002;41 (7):868-74.

9. Liddle HA, Rowe CL, Dakof GA, Henderson CE, Greenbaum PE. Multidimensional family therapy for young adolescent substance abuse: twelve-month outcomes of a randomized controlled trial. J Consult Clin Psychol. 2009;77(1):12-25.

10. Sexton $\mathrm{T}$, Turner $\mathrm{CW}$. The effectiveness of functional family therapy for youth with behavioral problems in a community practice setting. J Fam Psychol. 2010;24(3):339-48.

11. College voor Zorgverzekeringen. Dutch guidelines for pharmacoeconomic research. revised ed. Diemen: College voor Zorgverzekeringen; 2006.

12. National Institute for Health and Care Excellence: Guide to the methods of technology appraisal; 2013

13. Goorden M, Van Der Schee E, Hendriks VM, Hakkaart-van Roijen L. Costeffectiveness of multidimensional family therapy compared to cognitive behavioral therapy for adolescents with a cannabis use disorder: Data from a randomized controlled trial. Drug Alcohol Depend. 2016, May 1;162:154-61.

14. Brazier J. Is the EQ-5D fit for purpose in mental health? Br J Psychiatry. 2010;197(5):348-9.

15. Knapp M, Mangalore R. The trouble with QALYs. Epidemiol Psychiatr Soc. 2007;16(4):289-93.

16. Brooks R, Group E. EuroQol: the current state of play. Health Policy. 1996;37(1):53-72.

17. Al-Janabi H, Flynn TN, Coast J. Estimation of a preference-based carer experience scale. Med Decis Mak. 2011;31(3):458-68.

18. Al-Janabi H, Coast J, Flynn TN. What do people value when they provide unpaid care for an older person? A meta-ethnography with interview follow-up. Soc Sci Med. 2008;67(1):111-21.

19. Sanders GD, Neumann PJ, Basu A, Brock DW, Feeny D, Krahn M, Kuntz KM Meltzer DO, Owens DK, Prosser LA, Salomon JA. Recommendations for conduct, methodological practices, and reporting of cost-effectiveness analyses: second panel on cost-effectiveness in health and medicine. JAMA. 2016;316(10):1093-103.

20. Goorden M, Schawo SJ, Bouwmans-Frijters CA, van der Schee E, Hendriks VM, Hakkaart-van RL. The cost-effectiveness of family/familybased therapy for treatment of externalizing disorders, substance use disorders and delinquency: a systematic review. BMC Psychiatry. 2016; 16(1):237

21. Jofre-Bonet M, Sindelar JL. Creating an aggregate outcome index: costeffectiveness analysis of substance abuse treatment. J Behav Health Serv Res. 2004;31(3):229-41.

22. Deas D, Thomas SE. An overview of controlled studies of adolescent substance abuse treatment. Am J Addict. 2001;10(2):178-89.

23. Hogue A, Liddle HA. Family-based treatment for adolescent substance abuse: controlled trials and new horizons in services research. J Fam Ther. 2009:31(2):126-54

24. McLellan AT, Luborsky L, Woody GE, O'Brien CP. An improved diagnostic evaluation instrument for substance abuse patients. The Addiction Severity Index. J Nerv Ment Dis. 1980;168(1):26-33.

25. Bronfenbrenner U. Contexts of child rearing: problems and prospects. Am Psychol. 1979;34(10):844

26. Hinton WJ, Sheperis C, Sims P. Family-based approaches to juvenile delinquency: a review of the literature. Fam J Alex Va. 2003;11(2):167-73. 
27. Moher D, Liberati A, Tetzlaff J, Altman DG, Prisma Group. Preferred reporting items for systematic reviews and meta-analyses: the PRISMA statement. PLoS Med. 2009;6(7):e1000097.

28. Ryan M, Gerard K. Using discrete choice experiments to value health care programmes: current practice and future research reflections. Appl Health Econ Health Policy. 2003;2(1):55-64.

29. Witt J, Scott A, Osborne R. Designing choice experiments with many attributes. An application to setting priorities for orthopaedic waiting lists. J Health Econ. 2009;18:681-96.

30. Friedman AS, Utada A. A method for diagnosing and planning the treatment of adolescent drug abusers (the Adolescent Drug Abuse Diagnosis [ADAD] instrument). J Drug Educ. 1989;19(4):285-312.

31. Chinet $L$, Plancherel $B$, Bolognini M, Holzer $L$, Halfon O. Adolescent substance-use assessment: methodological issues in the use of the Adolescent Drug Abuse Diagnosis (ADAD). Subst Use Misuse. 2007;42(10):1505-25.

32. European Monitoring Centre for Drugs and Drug Addiction. Adolescent Drug Abuse Diagnosis [http://www.emcdda.europa.eu/html.cfm/ index3530EN.html].

33. Czobor P, Bacskai E, Oberg D, Haack MJ, Gerevich J. The European Adolescent Assessment Dialogue (EuroADAD): a psychometric evaluation. Eur Addict Res. 2011;17(6):302-15

34. Winters KC, Stinchfield RD, Fulkerson J, Henly GA. Measuring alcohol and cannabis use disorders in an adolescent clinical sample. Psychol Addict Behav. 1993;7(3):185-96.

35. Winters KC, Stinchfield RD, Henly GA. Further validation of new scales measuring adolescent alcohol and other drug abuse. J Stud Alcohol. 1993;54(5):534-41.

36. European Monitoring Centre for Drugs and Drug Addiction. Adolescent Diagnostic Interview (ADI) [http://www.emcdda.europa.eu/attachements. cfm/att 4137_EN tadi.pdf.]

37. Hodges K, Wong MM. Psychometric characteristics of a multidimensional measure to assess impairment: the child and adolescent functional assessment scale. J Child Fam Stud. 1996;5(4):445-67.

38. Multi-Health Systems Inc. CAFAS - Child and Adolescent Functional Assessment Scale. [http://www.mhs.com/product.aspx?gr=cli\&prod=cafas\&id=overview].

39. Dennis M, Godley SH, Diamond G, Tims FM, Babor T, Donaldson J, et al. The Cannabis Youth Treatment (CYT) Study: main findings from two randomized trials. J Subst Abus Treat. 2004;27(3):197-213.

40. Chestnut Health Systems. Gain Global Appraisal of Individual Needs. [http://gaincc.org/about/]

41. GAIN Coordinating Center. GAIN - Global Appraisal of Individual Needs. [http://gaincc.org/instruments/.]

42. Rahdert E R: The Adolescent Assessment/Referral System Manual 1991

43. Kaminer $Y$, Bukstein O, Tarter RE. The Teen-Addiction Severity Index: rationale and reliability. Int J Addict. 1991;26(2):219-26.

44. Kaminer, Y: Teen Addiction Severity Index (T-ASI). [http://www.emcdda. europa.eu/attachements.cfm/att_4008_EN_tt-asi.pdf].

45. Brodey BB, McMullin D, Kaminer Y, Winters KC, Mosshart E, Rosen CS, et al. Psychometric characteristics of the Teen Addiction Severity Index-Two (T-ASI-2). Substance abuse. 2008;29(2):19-32.

46. Washington State Institute for Public Policy. Washington State Juvenile Court Assessment Manual Version 1999 2.0. [http://www.wsipp.wa.gov/ rptfiles/99-01-0000.pdf].

47. Liddle HA, Rowe CL, Dakof GA, Ungaro RA, Henderson CE. Early intervention for adolescent substance abuse: pretreatment to posttreatment outcomes of a randomized clinical trial comparing multidimensional family therapy and peer group treatment. J Psychoactive Drugs. 2004;36(1):49-63.

48. Chestnut Health Systems. . GAIN-SS. [http://gaincc.org/gainss].

49. Hendriks VM, Kaplan CD, van Limbeek J, Geerlings P. The Addiction Severity Index: reliability and validity in a Dutch addict population. J Subst Abus Treat. 1989:6(2):133-41.

50. Leonhard C, Mulvey K, Gastfriend DR, Shwartz M. The Addiction Severity Index: a field study of internal consistency and validity. J Subst Abus Treat. 2000;18(2):129-35.

51. McLellan AT, Luborsky L, Cacciola J, Griffith J, Evans F, Barr HL, et al. New data from the Addiction Severity Index. Reliability and validity in three centers. J Nerv Ment Dis. 1985;173(7):412-23.

52. Zanis DA, McLellan AT, Cnaan RA, Randall M. Reliability and validity of the Addiction Severity Index with a homeless sample. J Subst Abus Treat. 1994;11(6):541-8.
53. Kaminer Y, Wagner E, Plummer B, Seifer R. Validation of the Teen Addiction Severity Index (T-ASI). American Academy of Psychiatrists in Alcoholism and Addictions. 1993;2(3):250-4.

54. COMET (Core Outcome Measures in Effectiveness Trials) Initiative. http:// www.comet-initiative.org/.

55. Schippers G, Broekman T. MATE-Y 2.1a - handleiding en protocol voor de MATE-jeugd. Beta Boeken: Nijmegen; 2013.

56. Gold M, Siegel J, Russel L, Weinstein M. Cost-Effectiveness in Health and Medicine. New York: Oxford University Press; 1996.

57. van der Zanden BP, Dijkgraaf MG, Blanken P, de Borgie CA, van Ree JM, van den Brink W. Validity of the EQ-5D as a generic health outcome instrument in a heroin-dependent population. Drug Alcohol Depend. 2006:82(2):111-8.

58. Pyne JM, French M, McCollister K, Tripathi S, Rapp R, Booth B. Preferenceweighted health-related quality of life measures and substance use disorder severity. Addiction. 2008;103(8):1320-9. discussion 1330-2

59. Pyne JM, Tripathi S, French M, McCollister K, Rapp RC, Booth BM. Longitudinal association of preference-weighted health-related quality of life measures and substance use disorder outcomes. Addiction. 2011;106(3):507-15.

\section{References (systematic review results; see Table 2 \& Table 3)}

1. Armelius BA, Andreassen TH. Cognitive-behavioral treatment for antisocial behavior in youth in residential treatment. Cochrane Database Syst Rev. 2007:4(4):CD005650.

2. Arnold EM, Kirk RS, Roberts AC, Griffith DP, Meadows K, Julian J. Treatment of incarcerated, sexually-abused adolescent females: an outcome study. J Child Sex Abus. 2003;12(1):123-39.

3. Azzopardi PS, Kennedy EC, Patton GC, Power R, Roseby RD, Sawyer SM, et al. The quality of health research for young Indigenous Australians: systematic review. Med J Aust. 2013;199(1):57-63.

4. Baldwin SA, Christian S, Berkeljon A, Shadish WR. The effects of family therapies for adolescent delinquency and substance abuse: a meta-analysis. J Marital Fam Ther. 2012;38(1):281-304.

5. Borduin CM. Multisystemic treatment of criminality and violence in adolescents. J Am Acad Child Adolesc Psychiatry. 1999;38(3):242-9.

6. Borduin CM. Multisystemic treatment of criminality and violence in adolescents. J Am Acad Child Adolesc Psychiatry. 1999;38(3):242-9.

7. Borduin CM, Schaeffer CM, Heiblum N. A randomized clinical trial of multisystemic therapy with juvenile sexual offenders: effects on youth social ecology and criminal activity. J Consult Clin Psychol. 2009;77(1):26-37.

8. Brown SA, D'Amico EJ. Outcomes of alcohol treatment for adolescents. Recent Dev Alcohol. 2003;16:289-312.

9. Brown SA, D'Amico EJ, McCarthy DM, Tapert SF. Four-year outcomes from adolescent alcohol and drug treatment. J Stud Alcohol. 2001;62(3):381-8.

10. Burleson JA, Kaminer Y. Self-efficacy as a predictor of treatment outcome in adolescent substance use disorders. Addict Behav. 2005;30(9):1751-64.

11. Chamberlain $P$, Leve LD, Degarmo DS. Multidimensional treatment foster care for girls in the juvenile justice system: 2-year follow-up of a randomized clinical trial. J Consult Clin Psychol. 2007:75(1):187-93.

12. Cornelius JR, Douaihy A, Bukstein OG, Daley DC, Wood SD, Kelly TM, et al. Evaluation of cognitive behavioral therapy/motivational enhancement therapy (CBT/MET) in a treatment trial of comorbid MDD/AUD adolescents. Addict Behav. 2011:36(8):843-8.

13. Cottrell D, Boston P. Practitioner review: the effectiveness of systemic family therapy for children and adolescents. J Child Psychol Psychiatry. 2002;43(5):573-86.

14. Curtis NM, Ronan KR, Borduin CM. Multisystemic treatment: a meta-analysis of outcome studies. Journal of family. 2004;18(3):411-9.

15. D'Amico EJ, Ellickson PL, Wagner EF, Turrisi R, Fromme K, Ghosh-Dastidar B, et al. Developmental considerations for substance use interventions from middle school through college. Alcohol Clin Exp Res. 2005;29(3):474-83.

16. Deas D. Evidence-based treatments for alcohol use disorders in adolescents. Pediatrics. 2008;121(Suppl 4):S348-54.

17. Deas D, Thomas SE. An overview of controlled studies of adolescent substance abuse treatment. The American Journal on Addictions / American Academy of Psychiatrists in Alcoholism and Addictions. 2001; 10(2):178-89.

18. Dembo R, Shemwell M, Guida J, Schmeidler J, Pacheco K, Seeberger W. A Longitudinal Study of the Impact of a Family Empowerment Intervention on Juvenile Offender Psychosocial Functioning: A First Assessment. J Child Adolesc Subst Abuse. 1998;8(1):15-54. 
19. Dembo R, Wothke W, Livingston S, Schmeidler J. The impact of a family empowerment intervention on juvenile offender heavy drinking: a latent growth model analysis. Subst Use Misuse. 2002;37(11):1359-90.

20. Dennis M, Godley SH, Diamond G, Tims FM, Babor T, Donaldson J, et al. The Cannabis Youth Treatment (CYT) Study: main findings from two randomized trials. J Subst Abus Treat. 2004;27(3):197-213.

21. Dennis M, Titus JC, Diamond G, Donaldson J, Godley SH, Tims FM, et al. The Cannabis Youth Treatment (CYT) experiment: rationale, study design and analysis plans. Addiction. 2002;97(Suppl 1):16-34

22. Diamond G, Josephson A. Family-based treatment research: a 10-year update. J Am Acad Child Adolesc Psychiatry. 2005;44(9):872-87.

23. Ferguson LM, Wormith JS. A meta-analysis of moral reconation therapy. Int J Offender Ther Comp Criminol. 2012;

24. Gil AG, Wagner EF, Tubman JG. Culturally sensitive substance abuse intervention for Hispanic and African American adolescents: empirical examples from the Alcohol Treatment Targeting Adolescents in Need (ATTAIN) Project. Addiction. 2004;99(Suppl 2):140-50.

25. Glisson C, Schoenwald SK, Hemmelgarn A, Green P, Dukes D, Armstrong KS, et al. Randomized trial of MST and ARC in a two-level evidence-based treatment implementation strategy. J Consult Clin Psychol. 2010;78(4):537-50.

26. Godley SH, Garner BR, Passetti LL, Funk RR, Dennis ML, Godley MD. Adolescent outpatient treatment and continuing care: main findings from a randomized clinical trial. Drug Alcohol Depend. 2010;110(1-2):44-54.

27. Godley SH, Hedges K, Hunter B. Gender and racial differences in treatment process and outcome among participants in the adolescent community reinforcement approach. Psychol Addict Behav. 2011;25(1):143-54.

28. Hall JA, Smith DC, Easton SD, An H, Williams JK, Godley SH, et al. Substance abuse treatment with rural adolescents: issues and outcomes. J Psychoactive Drugs. 2008;40(1):109-20.

29. Harold GT, Kerr DC, Van Ryzin M, Degarmo DS, Rhoades KA, Leve LD. Depressive Symptom Trajectories Among Girls in the Juvenile Justice System: 24-month Outcomes of an RCT of Multidimensional Treatment Foster Care. Prev Sci. 2013;

30. Henderson CE, Dakof GA, Greenbaum PE, Liddle HA. Effectiveness of multidimensional family therapy with higher severity substance-abusing adolescents: report from two randomized controlled trials. J Consult Clin Psychol. 2010;78(6):885-97.

31. Henggeler SW, Halliday-Boykins CA, Cunningham PB, Randall J, Shapiro SB, Chapman JE. Juvenile drug court: enhancing outcomes by integrating evidence-based treatments. J Consult Clin Psychol. 2006;74(1):42-54.

32. Henggeler SW, McCart MR, Cunningham PB, Chapman JE. Enhancing the effectiveness of juvenile drug courts by integrating evidence-based practices. J Consult Clin Psychol. 2012;80(2):264-75.

33. Henggeler SW, Melton GB, Brondino MJ, Scherer DG, Hanley JH. Multisystemic therapy with violent and chronic juvenile offenders and their families: the role of treatment fidelity in successful dissemination. J Consult Clin Psychol. 1997;65(5):821-33.

34. Henggeler SW, Melton GB, Smith LA. Family preservation using multisystemic therapy: an effective alternative to incarcerating serious juvenile offenders. J Consult Clin Psychol. 1992;60(6):953-61.

35. Henggeler SW, Pickrel SG, Brondino MJ. Multisystemic treatment of substance-abusing and dependent delinquents: outcomes, treatment fidelity, and transportability. Ment Health Serv Res. 1999;1(3):171-84.

36. Henggeler SW, Sheidow AJ. Empirically supported family-based treatments for conduct disorder and delinquency in adolescents. J Marital Fam Ther. 2012;38(1):30-58.

37. Henggeler SW, Sheidow AJ. Conduct disorder and delinquency. J Marital Fam Ther. 2003;29(4):505-22

38. Hogue A, Dauber S, Stambaugh LF, Cecero JJ, Liddle HA. Early therapeutic alliance and treatment outcome in individual and family therapy for adolescent behavior problems. J Consult Clin Psychol. 2006;74(1):121-9.

39. Hogue A, Henderson CE, Dauber S, Barajas PC, Fried A, Liddle HA. Treatment adherence, competence, and outcome in individual and family therapy for adolescent behavior problems. J Consult Clin Psychol. 2008;76(4):544-55.

40. Hogue A, Liddle HA. Family-based treatment for adolescent substance abuse: controlled trials and new horizons in services research. J Fam Ther. 2009;31(2):126-54.

41. Hunter SB, Ramchand R, Griffin BA, Suttorp MJ, McCaffrey D, Morral A. The effectiveness of community-based delivery of an evidence-based treatment for adolescent substance use. J Subst Abus Treat. 2012;43(2):211-20.

42. Kaminer $Y$, Burleson JA. Does temperament moderate treatment response in adolescent substance use disorders? Subst Abus. 2008;29(2):89-95.
43. Kaminer Y, Burleson JA, Goldberger R. Cognitive-behavioral coping skills and psychoeducation therapies for adolescent substance abuse. J Nerv Ment Dis. 2002;190(11):737-45

44. Kaminer Y, Burleson JA, Goldston DB, Burke RH. Suicidal ideation among adolescents with alcohol use disorders during treatment and aftercare. The American Journal on Addictions / American Academy of Psychiatrists in Alcoholism and Addictions. 2006;15(Suppl 1):43-9.

45. Keiley MK. Multiple-family group intervention for incarcerated adolescents and their families: a pilot project. J Marital Fam Ther. 2007;33(1):106-24.

46. Killeen TK, McRae-Clark AL, Waldrop AE, Upadhyaya H, Brady KT. Contingency management in community programs treating adolescent substance abuse: a feasibility study. J Child Adolesc Psychiatr Nurs. 2012; 25(1):33-41.

47. Latimer WW, Winters KC, D'Zurilla T, Nichols M. Integrated family and cognitive-behavioral therapy for adolescent substance abusers: a stage I efficacy study. Drug Alcohol Depend. 2003;71(3):303-17.

48. Letourneau EJ, Henggeler SW, Borduin CM, Schewe PA, McCart MR, Chapman JE, et al. Multisystemic therapy for juvenile sexual offenders: 1-year results from a randomized effectiveness trial. J Fam Psychol. 2009;23(1):89-102.

49. Liddle HA, Dakof GA, Parker K, Diamond GS, Barrett K, Tejeda M. Multidimensional family therapy for adolescent drug abuse: results of a randomized clinical trial. Am J Drug Alcohol Abuse. 2001;27(4):651-88.

50. Liddle HA, Dakof GA, Turner RM, Henderson CE, Greenbaum PE. Treating adolescent drug abuse: a randomized trial comparing multidimensional family therapy and cognitive behavior therapy. Addiction. 2008;103(10): 1660-70.

51. Liddle HA, Rowe CL, Dakof GA, Henderson CE, Greenbaum PE. Multidimensional family therapy for young adolescent substance abuse: twelve-month outcomes of a randomized controlled trial. J Consult Clin Psychol. 2009;77(1):12-25.

52. Liddle HA, Rowe CL, Dakof GA, Ungaro RA, Henderson CE. Early intervention for adolescent substance abuse: pretreatment to posttreatment outcomes of a randomized clinical trial comparing multidimensional family therapy and peer group treatment. J Psychoactive Drugs. 2004;36(1):49-63.

53. Littell JH, Popa M, Forsythe B. Multisystemic Therapy for social, emotional, and behavioral problems in youth aged 10-17. Cochrane Database Syst Rev. 2005;4(4):CD004797.

54. Lott DC, Jencius S. Effectiveness of very low-cost contingency management in a community adolescent treatment program. Drug Alcohol Depend. 2009:102(1-3):162-5.

55. Marsden J, Stillwell G, Barlow H, Boys A, Taylor C, Hunt N, et al. An evaluation of a brief motivational intervention among young ecstasy and cocaine users: no effect on substance and alcohol use outcomes. Addiction. 2006;101(7):1014-26.

56. Martin G, Copeland J. The adolescent cannabis check-up: randomized trial of a brief intervention for young cannabis users. J Subst Abus Treat. 2008:34(4):407-14.

57. McCambridge J, Strang J. The efficacy of single-session motivational interviewing in reducing drug consumption and perceptions of drug-related risk and harm among young people: results from a multi-site cluster randomized trial. Addiction. 2004;99(1):39-52.

58. McGlynn AH, Hahn P, Hagan MP. The Effect of a Cognitive Treatment Program for Male and Female Juvenile Offenders. Int J Offender Ther Comp Criminol. 2012;

59. Moore SK, Marsch LA, Badger GJ, Solhkhah R, Hofstein Y. Improvement in psychopathology among opioid-dependent adolescents during behavioralpharmacological treatment. J Addict Med. 2011;5(4):264-71.

60. Randall J, Cunningham PB. Multisystemic therapy: a treatment for violent substance-abusing and substance-dependent juvenile offenders. Addict Behav. 2003;28(9):1731-9.

61. Rigter $\mathrm{H}$, Henderson CE, Pelc I, Tossmann P, Phan O, Hendriks V, et al. Multidimensional family therapy lowers the rate of cannabis dependence in adolescents: a randomised controlled trial in Western European outpatient settings. Drug Alcohol Depend. 2013;130(1-3):85-93.

62. Robbins MS, Feaster DJ, Horigian VE, Rohrbaugh M, Shoham V, Bachrach K, et al. Brief strategic family therapy versus treatment as usual: results of a multisite randomized trial for substance using adolescents. J Consult Clin Psychol. 2011;79(6):713-27.

63. Robbins MS, Szapocznik J, Dillon FR, Turner CW, Mitrani VB, Feaster DJ. The efficacy of structural ecosystems therapy with drug-abusing/dependent African American and Hispanic American adolescents. J Fam Psychol. 2008;22(1):51-61. 
64. Rohde P, Jorgensen JS, Seeley JR, Mace DE. Pilot evaluation of the Coping Course: a cognitive-behavioral intervention to enhance coping skills in incarcerated youth. J Am Acad Child Adolesc Psychiatry. 2004;43(6):669-76.

65. Sealock M, Gottfredson D, Gallagher C. Drug Treatment for Juvenile Offenders: Some Good and Bad News. J Res Crime Delinq. 1997;34(2):210-36.

66. Sexton T, Turner $\mathrm{CW}$. The effectiveness of functional family therapy for youth with behavioral problems in a community practice setting. J Fam Psychol. 2010;24(3):339-48.

67. Smith DC, Hall JA, Williams JK, An H, Gotman N. Comparative efficacy of family and group treatment for adolescent substance abuse. The American Journal on Addictions / American Academy of Psychiatrists in Alcoholism and Addictions. 2006;15(Suppl 1):131-6.

68. Tanner-Smith EE, Wilson SJ, Lipsey MW. The comparative effectiveness of outpatient treatment for adolescent substance abuse: a meta-analysis. J Subst Abus Treat. 2013;44(2):145-58.

69. Timmons-Mitchell J, Bender MB, Kishna MA, Mitchell CC. An independent effectiveness trial of multisystemic therapy with juvenile justice youth. J Clin Child Adolesc Psychol. 2006;35(2):227-36.

70. Tripodi SJ, Bender K, Litschge C, Vaughn MG. Interventions for reducing adolescent alcohol abuse: a meta-analytic review. Arch Pediatr Adolesc Med. 2010;164(1):85-91.

71. Waldron HB, Kaminer Y. On the learning curve: the emerging evidence supporting cognitive-behavioral therapies for adolescent substance abuse. Addiction. 2004;99(Suppl 2):93-105.

72. Waldron HB, Kern-Jones S, Turner CW, Peterson TR, Ozechowski TJ. Engaging resistant adolescents in drug abuse treatment. J Subst Abus Treat. 2007;32(2):133-42.

73. Waldron HB, Slesnick N, Brody JL, Turner CW, Peterson TR. Treatment outcomes for adolescent substance abuse at 4- and 7-month assessments. J Consult Clin Psychol. 2001;69(5):802-13.

74. Waldron HB, Turner CW. Evidence-based psychosocial treatments for adolescent substance abuse. Journal of clinical child and adolescent. 2008;37(1):238-61.

75. Walker DD, Stephens R, Roffman R, Demarce J, Lozano B, Towe S, et al. Randomized controlled trial of motivational enhancement therapy with nontreatment-seeking adolescent cannabis users: a further test of the teen marijuana check-up. Psychol Addict Behav. 2011;25(3):474-84.

76. Walker DF, McGovern SK, Poey EL, Otis KE. Treatment effectiveness for male adolescent sexual offenders: a meta-analysis and review. J Child Sex Abus. 2004:13(3-4):281-93.

77. Winters KC, Fahnhorst T, Botzet A, Lee S, Lalone B. Brief intervention for drug-abusing adolescents in a school setting: outcomes and mediating factors. J Subst Abus Treat. 2012;42(3):279-88.

78. Winters KC, Leitten W. Brief intervention for drug-abusing adolescents in a school setting. Psychol Addict Behav. 2007;21(2):249-54.

79. Winters KC, Stinchfield RD, Opland E, Weller C, Latimer WW. The effectiveness of the Minnesota Model approach in the treatment of adolescent drug abusers. Addiction. 2000;95(4):601-12.

80. Woolfenden SR, Williams K, Peat J. Family and parenting interventions in children and adolescents with conduct disorder and delinquency aged 10-17. Cochrane Database Syst Rev. 2001;2(2):CD003015.

\section{Submit your next manuscript to BioMed Central and we will help you at every step:}

- We accept pre-submission inquiries

- Our selector tool helps you to find the most relevant journal

- We provide round the clock customer support

- Convenient online submission

- Thorough peer review

- Inclusion in PubMed and all major indexing services

- Maximum visibility for your research

Submit your manuscript at www.biomedcentral.com/submit 